\title{
AVERROES Y EL ENTENDIMIENTO
}

\author{
Josep Puig Montada \\ Universidad Complutense de Madrid
}

\section{RESUMEN}

Para Averroes, el libro de Aristóteles Acerca del alma era su fuente de información para conocer el proceso cognitivo en su conjunto: no tan sólo la parte de nuestro conocimiento a nivel del entendimiento, sino también las fases a nivel de los sentidos e intermedias entre estos y el entendimiento.

El propósito del artículo es, pues, una interpretación del comentario mayor de Averroes al De anima como un examen de cómo el hombre obtiene las diferentes clases de conocimiento, que se completa con una investigación acerca de los fundamentos metafísicos de la teoría averroísta del conocimiento.

Palabras clave: Averroes, entendimiento, ciencia cognitiva.

\begin{abstract}
In its reading of Aristotle's book On the Soul, Averroes was not only interested in the knowledge acquired by the intellect but also in the sensationary and post-sensationary stages of our cognitive process.

The paper attempts at an interpretation of Averroes' Long Commentary On the Soul as an analysis of how man elaborates the different kinds of cognition, as well as it enquiries on the metaphysical foundations of Averroes' theory of knowledge.
\end{abstract}

Key words: Averroes, intellect, cognitive process.

Nuestro proceso de conocer transcurre por una zona difusa entre unos términos que son los datos sensibles y principios universales. En su lectura de Aristóteles, la filosofía árabe se interesó en particular por la segunda dirección, la intelectual, pero prestó menos atención a los procesos y en cambio tendió a definir unas entidades hipostasiadas.

Jean Jolivet, en su estudio sobre al-Kindî (m. ca. 870) ${ }^{1}$, Rafael Ramón, en el suyo sobre Alfarabi (m. 950) ${ }^{2}$, M. Cruz Hernández y Joaquín Lomba en sus presentes contribuciones sobre Avicena (980-1037) y Avempace (1085/1090-1131) respectivamente, o Herbert Davidson en su análisis de conjunto que culmina en Averroes (1126-1198) ${ }^{3}$, entre otros, hacen justicia a esta dimensión en el ámbito de los principales filósofos árabes. Todos estos pensadores hacen del entendimiento o intelecto la principal entidad en un sistema no tan sólo del conocimiento sino metafísico.

$1 \quad$ L'intellect selon Kindî. Leiden: Brill, 1971.

2 Contribución a la historia de la filosofía árabe. Alma e intelecto como problemas fundamentales de la misma. Madrid: CSIC, 1992

3 Alfarabi, Avicenna, and Averroes, on Intellect. Nueva York-Oxford: Oxford UP, 1992. 
En el origen de este desarrollo está el tratado aristotélico Acerca del alma ${ }^{4}$. El alma, nos dice, es «como el principio de los animales» (402 a 6-7). En cuanto a su esencia, los pensadores anteriores la definieron mediante uno de estos tres caracteres: el movimiento, la sensación, la incorporeidad (405 b 10-11), pero Aristóteles la define como substancia, y dentro de ésta como forma y realización $(\varepsilon v \tau \varepsilon \lambda \varepsilon \dot{\varepsilon} \chi\llcorner\alpha)$. Dado que la realización puede contener parte de posibilidad o potencia - en una primera fase- o no, como la ciencia respecto de la actividad de saber, hay que aclarar a qué clase pertenece el alma. Para Aristóteles, ella pertenece a la primera clase de realizaciones y es «la primera realización de un cuerpo natural y organizado» (412 b 5-6), que goza de vida «en potencia». Resuelto esto, Aristóteles se emplea a fondo en describir las funciones cuyo principio es el alma. El alma es principio de la nutrición, de la sen-

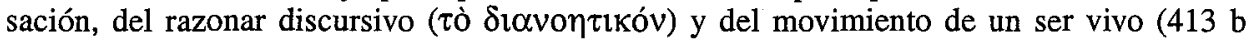
12-13).

La división entre sensación y razonamiento, sin embargo, no es absoluta y buena parte del análisis aristotélico está dedicado a unas fases intermedias. La sensación es definida por Aristóteles como «una especie de alteración» (416 b 34). Resulta que este proceso va luego acompañado de caracteres accidentales ( 428 b 19-20) y por último, de unos caracteres comunes, como movimiento local o reposo, número, figura, tiempo. En su De anima y también en sus opúsculos De sensu et sensato, De somno et vigilia, o De memoria et reminiscentia, Aristóteles indaga sobre una facultad sensible, no específica de un determinado órgano y capaz de sintetizar. «Los sensibles comunes los captamos mediante una percepción común, y que no es por accidente» (De anima 427 a 27), de ahí que tradicionalmente se denominara esta facultad sensus communis.

La imaginación está entre la sensación y el razonamiento discursivo (427 b 14-15): La percepción es un proceso, posible o actual, y cuando la percepción desaparece, nos deja una huella normalmente visual, que es una imagen $(\varphi \alpha \nu \tau \alpha \sigma i \alpha)$. Una diferencia notable es que mientras «las sensaciones siempre son verdaderas, las imágenes a menudo son falsas» (428 a 11-12).

Debemos añadir que, según Aristóteles, gracias a las imágenes podemos recordar. La memoria es una función corporal, activada por una percepción de una imagen similar a la que guardamos. Algunos animales tienen memoria, pero solamente el ser humano es consciente del fenómeno, y esta función es la llamada reminiscencia. Este recordar es una actividad voluntaria de búsqueda de datos que requiere el empleo de una facultad humana, la cogitativa ${ }^{5}$.

Sin embargo, el tratado De anima enlaza directamente el examen de la imaginación con el de la intelección ( $\tau$ ò vocî), un hecho no sin trascendencia. Entender es la actividad de una facultad, del «entendimiento del alma» y mediante esta facultad, el alma «razona y capta [ideas]» (429 a 23) ${ }^{6}$. Razonar es discurrir, un movimiento en el plano teórico similar al de amar y odiar en el plano práctico (408 b 24-28), dos dimensiones del entendimiento.

Parece que el peso de la imagen inclina la balanza en favor de la dimensión «visual» del entender. Nos debatimos en nuestro interior, damos vueltas y por fin, vemos. Ciertamente, vemos la imagen intelectual a través del entendimiento.

La imagen intelectual es, desde luego, distinta de la sensible porque es la auténtica forma de los seres, o su esencia: «el ser grande» o «el ser agua» (429 b 10-11). Estas esencias, además, pueden ser materiales o pueden existir independientemente de la materia.

4 Edición Beker, 402 a-435 b. Traducción española, Tomás Calvo Martínez, Madrid: Gredos, 1978 y reediciones.

5 De memoria 2, 451 b 19-20: «Por esto nosotros buscamos mediante el pensar [discursivo] lo que procede de un momento o de otro, de lo similar o de lo contrario. Esto es lo produce la reminiscencia».

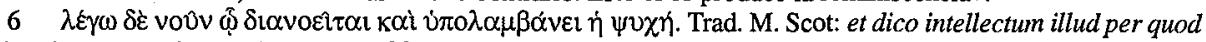
distinguimus et cogitamus (comparar 429 a 10-11). 
El hecho de que el objeto de aprehensión intelectual sea una forma implica lo siguiente: Así como la forma se debe unir a la materia para generar los seres, igualmente la forma se debe unir a una materia interior para generar el conocimiento. ¿Cuál es esta materia? ¿Cómo debe ser está materia?

Aristóteles habla de la tablilla de cera para escribir, y donde previamente nada está escrito «efectivamente» (430 a 1-2). Esta parece ser la materia. Ahora bien, las palabras de Aristóteles quieren decir algo más: esta tablilla es la metáfora de un entendimiento capaz de ser todas

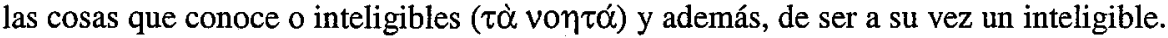

Aristóteles ve al entendimiento desde otro ángulo: cómo capaz de producir ( $\pi 0 t \varepsilon \hat{\imath} v)$ todas estas cosas (430 a 14-16). La metáfora elegida es la de la luz, que en su teoría de la visión, es el agente que hace pasar los colores en potencia a colores en acto.

Pero, ¿cuál es la naturaleza de los dos entendimientos? De las palabras de Aristóteles solamente queda claro que los dos son «diferencias» ( $\delta 1 \alpha \varphi \circ \rho \alpha i, 430$ a 14$)$ dentro del alma. No sabemos si son principios, causas, o substancias. Uno puede subsistir separado, o abstracto, y entonces es «lo que realmente es, y es inmortal y eterno», el otro no parece tener esta posibilidad de existir independientemente pues «es pasivo y perecedero».

Aristóteles explica el proceso cognitivo como el proceso de generación de una forma, pero luego reflexiona sobre las partes del alma implicadas: una puede ser substancia eterna, si se separa, es acto y es activa, la otra, por el contrario, no puede separarse, es potencia y es pasiva, además de ser como un material. Es una reflexión sorprendente, pero inacabada ${ }^{7}$. Es sorprendente porque aunque se origina en la experiencia material, termina en lo divino. Es obviamente inacabada y sus comentadores tratarán de completarla.

El entendimiento adquirirá mayor importancia y no sólo se distinguirá el entendimiento agente del material, sino que se hablará de un entendimiento en estado de posesión ( $\left.\varepsilon_{\xi} \xi_{1 \varsigma}\right) \mathrm{o}$ in habitu. Así lo hace Alejandro de Afrodisia (fl. ca. 200) en sus tratados Acerca del alma ${ }^{8}$, con una reciente traducción italiana de P. Accattino y de P. Donini ${ }^{9}$, o Acerca del entendimiento ${ }^{10}$, con varias traducciones, medievales y modernas, una de ellas en Two Greek Aristotelian Commentators on the Intellect ${ }^{11}$. El entendimiento in habitu es comparable al artesano, al que domina un oficio, aunque en este momento no lo ejerza, a diferencia del hombre que no lo domina, comparable al entendimiento material ${ }^{12}$. Por otra parte, Alejandro insiste en que el entendimiento agente, productor, viene «de fuera», abriendo camino a la instauración del Entendimiento Agente como una entidad supranatural que rige los acontecimientos del mundo sublunar.

En Temistio (317-388?) aparecen tres entendimientos, pero distintos de los de Alejandro. El entendimiento agente (o en acto) es equiparable en ambos autores, pero Temistio no es tan claro en situarlo «fuera». El entendimiento material se desdobla en potencial (ó $\delta v v \alpha ́ \mu \varepsilon 1$ ) y en común (Kolvós), como leemos en su paráfrasis al De anima ${ }^{13}$, también objeto de distintas traducciones ${ }^{14}$. El entendimiento común es inseparable del cuerpo y es perecedero, él es el sujeto de los procesos de razonamiento discursivo y operativo. El entendimiento en potencia es «abstracto, no está mezclado ni es pasivo... pero no es abstracto en el mismo sentido que el

7 Ver por ejemplo las incógnitas enumeradas por Octave Hamelin en La théorie de l'intellect d'après Aristote et ses commentateurs (Paris, 1953), pp. 25-28.

8 De anima Liber cum Mantissa. CAG, Supp. ar. II.1, ed. Ivo Bruns, Berlin 1887.

9 Alessandro di Afrodisia. L'anima. Roma-Bari: Laterza, 1996.

10 De anima Liber cum Mantissa. CAG, Supp. ar. II.1, pp. 106: 18-113: 24.

11 Translated by Frederic M. Schroeder, Toronto: Pontifical Institute of Mediaeval Studies, 1990.

12 De intellectu, 107: 22-25. Trad. Schroeder, p. 48.

13 Themistii in libros Aristotelis de anima paraphrasis. CAG V, ed. Richard Heinze, Berlin, 1899.

14 Traducción parcial de Robert B. Todd en Two Greek Aristotelian Commentators on the Intellect, pp. 75- 
agente», ${ }^{15}$ y este entendimiento en potencia puede convertirse en los objetos de pensamiento. Ocupa un rango intermedio entre el entendimiento material común y el entendimiento agente, pues es más actual que el común y menos que el agente ${ }^{16}$.

Averroes tendrá muy en cuenta estos dos comentadores griegos para leer el difícil pasaje aristotélico, además de recurrir a Alfarabi y de Avempace. A las distinciones adicionales ahora mencionadas, su vocabulario añade la de entendimiento adquirido para designar el tesoro de conocimientos «adquiridos». Emplea también el término de entendimiento teórico o especulativo, y como Averroes dice seguir a Alejandro al respecto, podemos asimilarlo al entendimiento in habitu ${ }^{17}$.

La mejor información, aunque no exclusiva, sobre el proceso cognitivo nos la proporciona Averroes en sus comentarios al De anima, y de los que nos han llegado todos los tres. El compendio o epítome fue editado por A.F. al-Ahwân $1^{18}$ y por S. Gómez Nogales, y la traducción española es del mismo ${ }^{19}$.

En cuanto a la exposición o talkhis que se ha conservado en árabe, Alfred Ivry lo ha editado en base a los dos manuscritos judeo-árabes conservados ${ }^{20}$ y de un número considerable de manuscritos conteniendo la doble traducción hebrea. Una traducción inglesa por Ivry acaba de aparecer $^{21}$ y existe una traducción, parcial, al francés ${ }^{22}$.

Del comentario mayor no conservamos ningún original árabe, y el manuscrito hebreo mencionado por Steinschneider es una traducción del latín, ${ }^{23}$ quizá del mismo 1475, fecha de su copia, según comprobó F. Stuart Crawford en su prólogo a la edición crítica de la traducción latina $^{24}$. Esta traducción latina es obra de Michael Scot, y se encuentra también en la edición de los hermanos Giunta ${ }^{25}$. Una parte importante, el libro III, ha sido traducido por A. de Libera al francés ${ }^{26}$. No voy a detenerme en la discusión sobre la cronología de estos comentarios y de sus revisiones, y aceptar que el gran comentario representa la versión más elaborada.

Como aristotélico Averroes tiene que partir de las impresiones en los sentidos como desencadenantes del proceso cognitivo. Encontramos, lógicamente, la distinción entre los sensibles propios y los comunes, que Averroes denomina a veces, según la traducción de M. Scot, universalia ${ }^{27}$. La facultad sensible del hombre tiene, según él, una capacidad que no tiene la facultad equivalente de los animales, a saber, «comprende las intentiones individuales, de los diferentes géneros y especies» ${ }^{28}$. Debemos considerar el sentido común como esta facultad sensible.

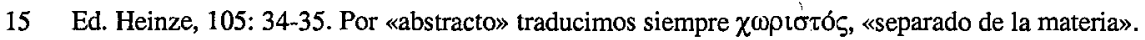

16 Ed. Heinze, p. 106: 7-14.

17 Temistio, como hemos dicho, piensa que el entendimiento agente, en cuanto alcanza el material, es el teórico. En cambio, Alejandro cree que el entendimiento in habitu (y que es el teórico) es distinto del entendimiento agente, y esto es lo que hay que creer, pues el arte es distinto del artefacto, y el agente, distinto del efecto (acto). Averrois Cordvbensis commentarivm magnvm in Aristotelis De anima libros. Ed. F. Stuart Crawford (Cambridge, Mass. 1953. Reprint Túnez, 1997), Libro III, página 447, líneas 127-132.

18 Talkhị̂ kitâb an-nafs. Cairo, 1950.

19 Epitome de anima. Madrid, 1985. Traducción en Psicología de Averroes, Madrid, 1987.

20 Talkhị̂ kitâb al-nafs. Cairo, 1994.

21 Averroës. Middle Commentary on Aristotle's De anima en la serie bilingüe Islamic Translation Series, de Brigham Young University Press, Provo, 2002.

22 Abdelali Elamarani-Jamal, «Averroès: la doctrine de l'intellect matériel dans le commentaire moyen au $D e$ anima d'Aristote», en Langages et philosophie. Hommage a Jean Jolivet (Paris, 1997), pp. 281-307.

23 Die hebräischen Übersetzungen des Mittelalters und die Juden als Dolmetscher (1893. Graz, 1956), p. 151.

24 Ver nota 17. Un profesor tunecino, B Gharbi, tradujo el latín al árabe, Túnez, 1998.

25 Aristotelis De anima libri tres cum Averrois commentariis, en Aristotelis opera cum Averrois commentariis. Suppl II, Venecia, apvd Iunctas, 1562-74. Reprint Frankfurt am Main 1962.

26 Averroès, L'intelligence et la pensée. Grand commentaire du "De anima». Livre III (429a10-435b25). Paris, 1998.

27 Commentarvm magnvm, ed. F.S. Crawford, 224: 23-24, correspondiendo a De anima 418 a 7-17. En adelante las citas al comentario mayor se refieren a este editor y se abrevian CM.

28 Los sentidos, cuando comprenden sus sensibles propios, comprenden las intentiones individuales, de los 
El término intentio traduce el árabe ma'nà que a su vez procede del griego $\lambda \varepsilon \kappa \tau o ́ v$, pero no debemos indagar en Aristóteles, sino en la tradición estoica que distingue entre la cosa, el significante y el significado, y tener presente la tradición teológica musulmana ${ }^{29}$. Es imposible traducir exactamente el término, y repetiré el término latino, bien afianzado, aunque Averroes no lo emplee como lo emplearon los escolásticos de los siglos XIII y XIV. El término aparece continuamente en Averroes, y M.A. Blaustein insiste en que para nuestro autor, todo el proceso cognitivo, tanto a nivel de imágenes como de inteligibles, debe ser interpretado en términos de una teoría de intentiones ${ }^{30}$ pero, ¿hasta qué punto Averroes era consciente de ella? Gätje pensaba que Averroes no era ni siquiera consecuente en su desarrollo ${ }^{31}$ y creo que, en efecto, no existe tal desarrollo, aunque sí una percepción muy clara de lo que es la intentio: la contrapartida interna al hombre de una forma externa. La intentio suele serlo de una forma de la imaginación y vemos que en su epítome del De sensu et sensibili distingue expresamente entre la intentio de la forma imaginada y su forma imaginada ${ }^{32}$. También puede serlo de un universal y así vemos cómo a propósito de la definición del entendimiento material, Averroes nos define el entendimiento material el lugar de todas las intentiones de universales ${ }^{33}$.

Unida a la intentio singular va la forma imaginada, que está revestida de los sensibles «comunes y propios». La facultad que la elabora es la ymaginatio. Nos escontramos, por tanto, en un estadio que Wolfson llamaba de las facultades «post-sensationary» ${ }^{34}$, y con procesos que Averroes entiende tienen su actividad en el cerebro, sin necesidad de órganos externos al mismo. En orden de mayor a menor materialidad tenemos estas cuatro facultades: sentido común, imaginación, cogitativa, memoria ${ }^{35}$. En cuanto a la imaginación, Averroes considera que los «griegos» la tomaban como entendimiento «en sentido amplio» ${ }^{36}$ y alguna vez él mismo

diferentes géneros y especies; comprenden, por tanto, la intentio de este hombre singular, o la intentio de este caballo singular, y [además] de manera universal, la intentio de cada uno de los diez predicamentos individuales. Está claro que esto es propio del hombre. CM II.63, 225: 44-51.

29 Sobre la importancia de la teoría del $m a$ 'nà en la teología musulmana, consolidada en el s. IX y por tanto anterior a Averroes, ver H.A. Wolfson, The Philosophy of Kalam (Harvard UP: 1976), pp. 147-167.

30 En su tesis doctoral de Harvard University: Averroes on the Imagination and the Intellect, 1984. University Microfilms International, Ann Arbor, 8503512. 299 pp. Cf. pp. 42-76.

31 «Die 'inneren Sinne' bei Averroes», ZDMG 115 (1965), p. 282.

32 Averrois Cordvbensis Compendia librorvm Aristotelis qvi Parva Natvralia vocantur. Ed. Henry Blumberg (Cambridge: The Mediaeval Academy of America, Mass. 1972), Talkhîs kitâb al-ḥass wa-l-mahsûs (CCAA VII), p. 40: 11-14: Aristóteles, para demostrar que esta facultad, es decir, la reminiscencia, es distinta de la facultad formativa (musawwira), y que son dos en cuanto a la quididad y al substrato, se basa en que a veces percibimos la intentio de la forma imaginada sin la forma imaginada, y otras, percibimos la forma sin despojarla de la intentio de la forma. Por esto podemos conservar la memoria de muchas cosas a la vez, y no podemos imaginarlas.

Otra edición, de A. Badawî, Talkhịs kitâb al-hass wa-l-mahsûs, en Aristûtâlî́s fî n-nafs; $2^{\mathrm{a}}$ ed. (Beirut-Kuwait, 1980) pp. 191-242, aquí p. 210: 14-18.

33 Es decir, la definición del entendimiento material es lo que es en potencia todas las intentiones de los seres materiales universales y en acto no es ninguno de los entes antes de entenderlo. Ya que ésta es la definición del entendimiento material, es evidente que difiere de la materia prima en que ese es en potencia todas las intentiones de las formas universales materiales, mientras que la materia prima es en potencia todas esta formas sensibles, sin conocerlas ni comprendiéndolas (CM III.5, 387: 22-388: 32).

34 «The Internal Senses in Latin, Arabic and Hebrew Philosophic Texts» (1935), reimpreso en Studies in the History of Philosophy and Religion, 2 vols., I. Twersky y G.H. Williams (eds.), vol. 1, (Cambridge: Harvard UP, 1973), pp. 250-285.

Se completa con el mencionado estudio de H. Gätje, «Die 'inneren Sinne' bei Averroes», ZDMG 115 (1965), pp. 255-293.

35 [Aristóteles] pone la reminiscencia como la más espiritual, luego la cogitativa, luego la imaginación y finalmente, la sensible (CM III.6, 416: 73-74).

36 A continuación dijo: y llamo entendimiento. etc. Es decir, con entendimiento designo la facultad del alma que se llama entendimiento en sentido propio, no en sentido amplio, o sea la facultad imaginativa en lengua griega (CM III.5, 387: 17-20, De anima 429 a 21-24). 
la califica de entendimiento ${ }^{37}$ ¿ ¿Cuál es su «sustancia y esencia»? Averroes la define como «un movimiento originado por la sensación en acto ${ }^{38}$, definición más precisa que la que hemos hallado en Aristóteles. Ambos coinciden en que la imaginación no es algo exclusivamente humano, pues no responde al criterio fundamental de ser verdadera o falsa -algo que requeriría nuestra «opinión» ${ }^{39}$ - de modo que incluso algunos animales poseen imaginación.

A continuación viene, pues, la facultad de la memoria. Averroes la examina en su Epítome del libro acerca de los sentidos y los sensible ${ }^{40}$, donde establece que dos facultades deben preceder a su funcionamiento: la sensible y la imaginativa ${ }^{41}$, y que los animales pueden tener cierto tipo de memoria. Sin embargo, el hombre además puede controlarla, recuperarla y gracias a la facultad cogitativa, relacionar las imágenes con sus objetos y emitir juicios de verdad, precisiones que hace al texto aristotélico y que reflejan discusiones posteriores ${ }^{42}$.

Llegamos pues a una tercera facultad post-sensorial, exclusiva del ser humano: la capacidad de asociar y de discriminar. Ambas actividades suelen aparecer unificadas en una misma capacidad $^{43}$. Además de las referencias que le dedica en su epítome De sensu et sensibili, Averroes la considera en su comentario mayor al De anima y en los otros comentarios, que R. Taylor ha analizado en dos recientes publicaciones ${ }^{44}$. Digamos brevemente que en el comentario mayor Averroes sostiene que estas tres facultades - imaginación, memoria y cogitativa - son corpóreas, materiales ${ }^{45}$, y que la actividad de la facultad cogitativa es doble: asociar la intentio de la imagen o forma imaginada con su correspondiente individuo, o bien distinguir entre la intentio y el individuo ${ }^{46}$. La primera operación, en el tiempo, es la discriminativa, la que dis-

37 El término «entendimiento», por tanto, se dice en este libro de cuatro maneras: Se dice del entendimiento material, del entendimiento in habitu, del entendimiento agente y de la facultad imaginativa (CM III.20, 452: 253-256)

38 Si se afirma que el único modo posible de los antes dichos, a saber o ciencia, o entendimiento, u opinión, o sensación, o un compuesto de ellos, o un motor originado por la sensación, del que no se derive ninguna absurdidad, es el movimiento por la sensación, por necesidad la imaginación tiene que ser un movimiento por causa de la sensación en acto (CM II.161, p. 376: 88-94, comentando 428 b 14-429 a 3).

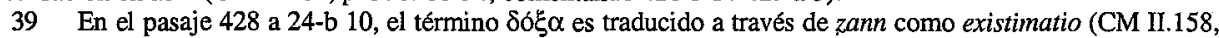
369: 1-10): La imaginación nunca puede estar compuesta de opinión más sentidos.

40 Citas en nota 33. Existe también una edición por H. Gätje, Die Epitome der Parva naturalia des Averroes, Wiesbaden, 1961.

41 .La facultad de los sentidos y la de la imaginación», qûwàt al-hass wa-qûuwat at-takhâyul: Talkhîs k. Hass, ed. Blumberg, p. 38: 8-9; ed. Badawî, p. 209: 12-13.

42 En cuanto a emitir un juicio acerca de si esta intentio [i.e., objeto] pertenece a esta imagen, es algo propio del hombre dotado de entendimiento, porque este es lo que juzga la afirmación y la negación. En los animales la memoria es algo parecido al entendimiento, porque esta facultad en el hombre emplea el pensamiento y la deliberación, y por esto se acuerda (yatadhakkar, reminiscencia). En los demás animales, es algo natural, y por esto los animales retienen en la memoria pero no se acuerdan. Esta facultad no tiene un nombre propio en los animales, es la que Avicena denomina «estimativa» (wahmîya). Talkhịs k. Hass, ed. Blumberg, p. 39: 6-10; ed. Badawî, pp. 209: 22-210: 2 .

43 Wolfson, «The Internal Senses», p. 289.

44 «Remarks on Cogitatio in Averroes' Commentarium Magnum in Aristotelis De Anima Libros», en G. Endress y J.A. Aertsen (eds.): Averroes and the Aristotelian Tradition, (Colonia, 1999), pp. 217-255. «Cogitatio, Cogitativus and Cogitare. Remarks on the Cogitative Power in Averroes», en J. Hamesse y C. Steel (eds.): L'élaboration du vocabulaire philosophique au moyen age, (Brepols, 2000), pp. 111-146.

45 La reminiscencia se produce mediante facultades comprensivas pasivas, es decir materiales. Son tres facultades, cuya esencia se ha explicado en el libro De sensu et sensatu, a saber, la imaginativa, la cogitativa y la reminiscencia. Estas facultades se encuentran en el hombre para presentarle la forma de la cosa imaginada cuando la sensación falta. Por esto se dice que cuando estas tres virtudes cooperan mutuamente, re-presentan la cosa individual, tal como es su esencia, aunque nosotros no la percibamos [en acto] (CM III.20, p. 449: 165-173).

46 [Aristóteles] se refiere con «entendimiento pasivo» a las formas de la imaginación en cuanto la facultad cogitativa propia del hombre actúa sobre ellas. Esta facultad es algo racional y su actividad consiste en asociar la intentio de la forma imaginada con su correspondiente individuo en un proceso de reminiscencia (rememoratio), o bien distinguir la forma de este, en un proceso de elaboración de forma [intelectual] y de imagen (CM III.20; p. 449: 173-182). 
tingue entre la forma y el individuo para obtener su imagen, y la segunda, en la asociativa, cuando nos facilita el recuerdo.

Que no nos quepa ninguna duda: la facultad cogitativa es corporal ${ }^{47}$. No es del entendi-

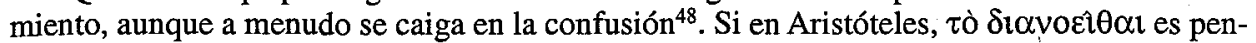
samiento discursivo - como a menudo también lo es voêt - la traducción latina nos da una distinctio perteneciente a esta facultad cogitativa. Así el pasaje aristotélico de 408 b 24-30, donde se habla del ejercicio del razonamiento discursivo, del amor y del odio, el pensamiento discursivo se queda en distinctio, a pesar de que la traducción árabe del De anima de Aristóteles lee tafakkur, y no tamyîz ${ }^{49}$. Los comentarios de Averroes insisten en este aspecto «discriminativo ${ }^{50}$, que nos permite captar la intentio individual.

Las tres, o cuatro, facultades post-sensoriales están al servicio del entendimiento, al que entregan estas «formas imaginadas» para que el entendimiento pueda conocer y entender. Ya

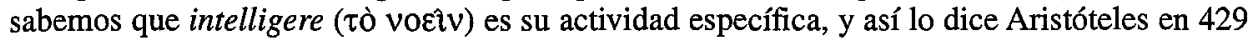
a 10-13, el pasaje donde empieza el Libro III del Comentario Mayor. Sin embargo, la traducción latina del pasaje que hizo M. Scot a partir del árabe, revela que el texto que utilizaba Averroes no coincidía con el de Aristóteles:

1. Pero, en cuanto a la parte del alma gracias a la cual ella conoce y entiende, (si es diferente o no en cuanto a magnitud, o sólo lo es en cuanto a intentio) debemos examinar la diferencia, cuál es, y de qué manera se forman conceptos por medio del entendimiento ${ }^{51}$.

Tò voદiv se ha convertido en formare per intellectum y el término árabe que está detrás sólo puede ser tașawwur, aunque la versión conservada del De anima no lo recoja ${ }^{52}$. H.A. Wolf$\operatorname{son}^{53}$, Gätje ${ }^{54}$ y, más recientemente y para Avicena, M. Maroth ${ }^{55}$ han considerado este término contrapuesto a tașdîq, que implica una asentimiento sobre la verdad o falsedad. Definámoslo

47 En el libro De sensu et sensato ya se ha explicado que éste es el orden de estas facultades cerebrales, mediante una demostracion de causa y existencia. Pero lo allí dicho no contradice lo que aquí se dice, pues según Aristóteles, la facultad cogitativa es una facultad distintiva individual, es decir, que no distingue más que lo individual, no lo universal. Se ha explicado que la facultad cogitativa es solamente la facultad que distingue la intentio de la cosa sensible de la imagen que la representa (idolo ymaginato). La relación que guarda con ambas inentiones, o sea, con la imagen de la cosa y con la intentio de su imagen, es como la relación del sentido común para con las intentiones de los cinco sentidos. Así pues, la facultad cogitativa pertenece al género de las virtudes existentes en los cuerpos (CM III. 6, 415: 56-68).

48 Ya hemos dicho que la facultad cogitativa no es el entendimiento material ni el en acto, sino que es una facultad material y particular. Esto se ve de lo dicho en el libro Acerca de los sentidos y los sensibles. Conviene saberlo porque se tiene la costumbre de atribuir la facultad cogitativa al entendimiento. Nadie debe afirmar que la facultad cogitativa compone los inteligibles singulares, ya se ha dicho que lo hace el entendimiento material, pues la cogitatio no es más que distinguir los individuos de sus correspondientes inteligibles... (CM III.33, 476: 62-71)

49 La alteración en el ámbito del pensamiento (discursivo = tafakkur), del amor y del odio no son accidentes del pensamiento, sino de la cosa y del sujeto en el que tiene lugar, en cuanto es su soporte (Aristutâtâlis fi n-nafs, ed. Badawî, p. 20).

50 Luego dice: Pero la distinción, el amor, y el odio, etc. Es decir: pero la distinción que se atribuye a la facultad cogitativa, y el amor y el odio, que se atribuyen a la razón, o sea, que reciben la acción de la razón. Está claro que en esta parte del alma hay algo racional que obedece al entendimiento, en los hombres buenos (CM I.66, 90: 37-45).

51 Es decir, distinción real o de razón.

52 De anima, Nafs, ed. Badawi, p. 72, no contiene y de qué manera se forman conceptos mediante el entendimiento, sino: ¿Cómo es la comprensión? En cuanto a conoce y entiende, por cognoscit et intelligit, corresponde

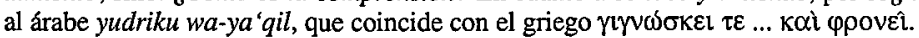

53 «The Terms tașawwur and tașitq in Arabic Philosophy and their Greek, Latin, and Hebrew Equivalents» (1943), en Studies in the History of Philosophy and Religion, vol. 1, pp. 478-492.

54 «Die 'inneren Sinne' bei Averroes», pp. 273-275.

55 Die Araber und die antike Wissenschaftstheorie (Budapest, 1994), pp. 77-78. 
como 'concepto' pero no olvidemos la dimensión visual, la misma que está en el término «idea», una forma en el entendimiento, distinta de ma 'qûl, el inteligible, en cuanto el segundo término destaca el ser objeto del 'aql, del entendimiento.

Así pues, formare per intellectum es el proceso que debemos explicar. Averroes habla de un proceso activo y otro receptivo-pasivo en el seno del alma racional.

Por una parte, el proceso de adquisición de los conceptos es receptivo. El carácter receptivo es algo que a Averroes le parece evidente, y basta, para él, la referencia a los sentidos. Estos son movidos por la intentiones sensibles, igual que el entendimiento humano - «el alma racional»- es movida por las intentiones existentes en las imágenes suministradas por las facultades post-sensoriales.

El esfuerzo de Averroes se centra, pues, en demostrar que formare per intellectum exige una facultad activa. Es imposible, según él, que estas formas puedan hacer mover el entendimiento, si antes este no ha procedido'a despojarlas de su materia y a hacerlas inteligibles en acto. «Así pues en cuanto los inteligibles la hacen mover [el alma racional] es pasiva, y en cuanto son movidas por ella, es activas ${ }^{56}$.

Averroes ha recurrido ahora al término, intellectum, «inteligible» ${ }^{57}$, aunque tanto inteligible, intentio como forma abstracta de la materia responden a un mismo objeto de la actividad de nuestro entendimiento, la intelección.

Hemos llegado, por tanto, a la facultad exclusiva del alma humana, una facultad doble, pero inmediatamente Averroes pasa a hablar de dos... substancias. ¿Por qué esta lectura? Evidentemente, a causa de toda la tradición greco-árabe sobre el entendimiento agente y el entendimiento material.

La aportación de Averroes, bien conocida y como ha señalado Davidson en la obra antes mencionada ${ }^{58}$, está relacionada con el entendimiento material más que con el entendimiento agente. Averroes evoluciona de una posición próxima a Alejandro de Afrodisia a otra cercana a Temistio, de modo que su concepción final del entendimiento receptivo es la de una substancia no generada ni destructible, separable, simple y que no es pasiva en el sentido de padecer alteraciones ${ }^{59}$. A pesar de ello Averroes tiene que definirlo como «un cuarto género de ser», es decir, no es forma, ni materia ni su compuesto ${ }^{60}$.

56 Digamos en consecuencia que concebir mediante el entendimiento pertenece de alguna manera a las facultades receptivas, como la facultad de los sentidos y, es evidente por lo siguiente: [porque] las facultades pasivas son movidas por aquello a lo que son atribuidas. En cambio las facultades activas son motrices de aquello a lo que són atribuidas. Puesto que nada hace mover más que en la medida en que está en acto, y es movido en la medida en que está en potencia, es necesario que las formas de las cosas, en cuanto están en acto fuera del alma, hagan mover el alma racional en cuanto las comprende de la misma manera como los sensibles en cuanto son seres en acto hacen mover los sentidos, y los sentidos son movidos por ellos. Por esto el alma racional debe examinar las intentiones que hay en la facultad imaginativa, tal como los sentidos deben mirar los inteligibles. Sin embargo, cuando uno ve que la formas de las cosas externas hacen mover esta facultad [sólo] cuando la mente-las despoja de sus materias, y las convierte por primera vez en inteligibles en acto, después que eran inteligibles en potencia, bajo este aspecto se ve que esta alma es activa, no pasiva. Así pues, en cuanto los inteligibles la hacen mover, es pasiva y, en cuanto son movidos por ella, es activa.

Por ello dice Aristóteles a continuación que en el alma racional hay que afirmar estas dos diferencias, es decir, la facultad de la acción y la facultad de la pasión. Dice claramente que ninguna de estas es generable ni corruptible, como se verá más adelante, pero aquí empezó explicando la sustancia de esta facultad pasiva, por ser necesario en la enseñanza. De ahí se demuestra que esta diferencia, la de la pasión y la acción, existe en la facultad racional (CM III.4, 384: 34-385: 62).

57 Como leemos en el mismo pasaje de Aristóteles, 429 a 17-18: como los sentidos respecto de los sensibles

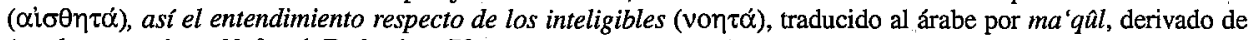
'aqala «entender», Nafs, ed. Badawî, p. 72.

58. Op. cit., capítulo «Averroes on the Material Intellect», pp. 258-314.

59 Esto mismo indujo a Teofrasto, a Temistio y a muchos comentadores a pensar que el entendimiento material es una substancia no generada ni destructible, pues todo lo que se genera y se destruye es algo concreto y determinado (hoc) y ya se ha demostrado que este entendimiento no es nada concreto, ni cuerpo ni forma en un cuer- 
La otra substancia existe en nuestras almas, en contra de la opinión de Alejandro de Afrodisia, es eterna, y está totalmente en acto. El entendimiento agente «desnuda» las formas de la materia y las hace inteligibles ${ }^{61}$, e incluso leemos que el entendimiento en acto hace los inteligibles $^{62}$. Sin embargo, Averroes prefiere hablar del entendimiento agente como aquel que hace que las intentiones de las formas imaginadas pasen de ser motrices en potencia a serlo encto, algo en consonancia con la explicación del proceso cognitivo que venimos escuchando ${ }^{63}$. Un ejemplo al que recurre en varias ocasiones es el de la luz, que hace que los colores pasen de la potencia al acto y puedan ser vistos, es decir, hagan mover ${ }^{64}$.

A Averroes le resultaba muy difícil volver al sentido original del texto aristotélico, ambiguo por lo demás, aunque su esfuerzo no perseguía otra cosa. Además se encontraba con dificultades de traducción, como es la del llamado entendimiento adquirido en Alejandro, mala traducción del vov̂s $\theta 0$ $\rho \alpha \theta \varepsilon v^{65}$, o sea una aspecto del entendimiento agente ${ }^{66}$. Alguna vez, Averroes termina sus intrincados razonamientos sobre la sustancia de uno y otro entendimiento con una constatación:

En general, cuando uno examina el entendimiento material junto con el agente, estos se le presentan como uno solo, en un aspecto, y como dos, en otro. Son dos en cuanto a las maneras de actuar: la acción del entendimiento agente es engendrar [formas inteligibles], la de este, ser «in-formado». Son uno en cuanto el entendimiento material llega a su per-

po. Esto fue lo que les llevó a creer que esta es la opinión de Aristóteles al respecto. Esta intención, es decir que este entendimiento es así, aparece bien clara a quienes examinan la demostración de Aristóteles y sus palabras. En cuanto a la demostración, es según lo que hemos expuesto. En cuanto a sus palabras, porque dijo que este entendimiento no es paciente, y que es separable y simple. Son tres términos empleados por Aristóteles para el entendimiento (CM III.5, 389: 57-68).

60 La tercera cuestión trata de cómo el entendimiento material es un existente de alguna manera, sin ser ninguna forma material ni materia prima y se resuelve como sigue: Debemos considerarlo un cuarto género de ser, pues así como cualquier ente sensible está dividido en materia y forma, el inteligible debe dividirse de manera parecida: en algo parecido a la forma y en algo parecido a la materia. Esto es algo necesario en cualquier inteligencia abstracta que entiende otra cosa que sí misma, pues de lo contrario no habría multiplicida en las formas abstractas (CM III.5, 409-410: 654-663).

61 Vieron esto confirmado por lo que Aristóteles puso de manifiesto que el entendimiento agente existe en nuestras almas ya que vemos que primero desnuda las formas y luego las entiende. «Desnudarlas» no consiste más que en hacerlas inteligibles en acto después de estar en potencia y «comprenderlas» no es más que recibirlas (CM III. 5, 390: 98-104).

62 «a acción propia del entendimiento agente es la producción de los inteligibles», facere intellecta, (CM III.20, 489: 290).

63 Por tanto debemos sostener lo que las palabras de Aristóteles nos han revelado, que en el alma hay dos partes del entendimiento, una es receptiva y su esencia se ha explicado aquí, y la otra, activa, y hace que las intentiones que hay en la facultad imaginativa muevan en acto el entendimiento material, después de haber sido motrices en potencia (CM III.5, 406: 556-562).

64 Debes saber que la relación (respectus) del entendimiento agente para con este entendimiento es como la de la luz para con el diáfano, y la relación de las formas materiales para con él, es como la relación del color para con el diáfano. De la misma manera como la luz es la perfección del diáfano, así el entendimiento agente es la perfección del entendimiento material, y de la misma manera que el diáfano no es movido por el color ni lo recibe más que cuando está iluminado, este entendimiento no recibe los inteligibles que aquí hay más que si es realizado e iluminado por aquel entendimiento. Del mismo modo que la luz hace pasar el color de la potencia al acto, de modo que este pueda mover el diáfano, así el entendimiento agente hace pasar las intentiones materiales de la potencia al acto, de modo que el entendimiento material las reciba (CM III.5, 410: 688-703).

65 J. Finnegan, «Texte arabe du $\tau \varepsilon \rho i$ voû d'Alexandre d'Aphrodise» en Mélanges de l'Université Saint Joseph 33 (1956), pp. 171-178: «Le terme intellectus adeptus...».

66 Un ejemplo de sus dificultades con esta traducción errónea:

Alejandro hablando de la existencia del entendimiento adquirido puede que diga que este no es una in-formación en el entendimiento material, hecha después de no existir, sino que [el adquirido] se une a nosotros de manera tal que es la forma mediante la cual entendemos los demás seres, esto es lo que Alejandro parece decir (CM III.36, 481: 58). 
fección por obra del entendimiento agente y lo entiende. Por esto decimos que en el entendimiento unido a nosotros se manifiestan dos facultades, una del género activo, otra del pasivo (CM III.20, 450: 213-451:222).

Estas palabras proceden de la parte final de su comentario mayor, Averroes parece haber vuelto al espíritu aristotélico de un solo voûs. En estas circunstancias, me voy a tomar la libertad de iniciar un nuevo recorrido, partiendo de la concepción que tiene Averroes del género humano. Lejos de toda idea evolucionista, pero también en contra de una idea de creación temporal de la especie humana, Averroes la concibe como eterna y por tanto, eternas deben ser sus causas. El entendimiento material, muy en particular, tiene que serlo como sujeto subyacente a la especie humana, y en cuanto tal le proporciona a esta unos principios comunes ${ }^{67}$. Los individuos, sin embargo, nacen y mueren, y con ellos sus conocimientos. Por esto Averroes piensa que el entendimiento que encontramos en cada uno de ellos, tiene que contener ambos elementos, lo eterno y lo temporal, y no puede ser la conjunción directa de dos entendimientos, el material y el agente, que son exclusivamente eternos y universales. Esta será su respuesta tanto al problema del conocimiento, de cómo es posible que seres individuales y perecederos tengan conocimientos universales y eternos, como al problema metafísico de una especie eterna pero unos individuos mortales.

Hasta aquí, la parte temporal de nuestro conocimiento ha venido proporcionada por las facultades post-sensoriales como «formas imaginadas», o intentiones imaginadas, gracias sobre todo a la facultad cogitativa. Ellas «in-forman» el entendimiento material presente en el individuo, de modo que nuestra unión con este entendimiento nunca es directa, sino a través de las formas imaginadas, y de una dimensión de ellas, la inteligible ${ }^{68}$.

Para llegar a ello, las intentiones tienen que actuar sobre el entendimiento material y lo hacen porque ellas tienen una fuerza motriz que reciben del entendimiento agente. De esta manera Averroes ha recogido los aspectos opuestos del entendimiento señalados por Aristóteles: material y formal, paciente y agente ${ }^{69}$. Sin embargo, ellos son distintos de nuestro entendimiento individual aquel que es una realidad, un hecho (factum).

Este entendimiento efectivo aparece asociado al entendimiento teórico (speculativus) y al entendimiento que está en disposición de actuar, el entendimiento in habitu. La acción de este último es extraer todos los inteligibles que queremos y actualizarlos después de estar en potencia. Hemos visto como el término $\check{\varepsilon} \xi ı$ aparece en Alejandro de Afrodisias, y Averroes está de acuerdo con él en que el entendimiento in habitu no es eterno y es el órgano intermedio para

67 Puesto que hemos sostenido en base a los argumentos precedentes que el entendimiento material es único para todos los hombres y de esto hemos deducido que la especie humana es eterna y así se ha expuesto en otros pasajes, es preciso que el entendimiento material no esté desprovisto de unos principios comunes a la especie humana, es decir, de unas primeras proposiciones y de unas ideas singulares, comunes a todos los hombres; estos inteligibles son uno en cuanto al recipiente, muchos en cuanto a la intentio recibida (CM III.5, 406: 575-407: 583).

68 Puesto que se ha probado en los anteriores razonamientos que el entendimiento no puede unirse con cada hombre y multiplicarse por el número de hombres, por la parte [del entendimiento] que es casi como materia, es decir: el entendimiento material, no queda otra opción más que la conjunción de la intentio intelecta con nosotros ( $\mathrm{y}$ son unas intentiones imaginadas), es decir, aquella parte de las intentiones imaginadas que está en nosotros y es casi una forma en cierto aspecto. Podemos decir que un niño es «inteligente» en potencia de dos maneras: una en el sentido de que las formas imaginadas que hay en él, son inteligibles en potencia, otra en el sentido de que el entendimiento material cuya naturaleza es recibir el inteligible de aquella forma imaginada, es un recipiente en potencia y está unido a nosotros en potencia (CM III.5, 404: 513-405: 527).

69 Por tanto debemos sostener lo que las palabras de Aristóteles nos han revelado, que en el alma hay dos partes del entendimiento, una es receptiva y su esencia se ha explicado aquí, y la otra, activa, y hace que las intentiones que hay en la facultad imaginativa muevan en acto el entendimiento material, después de haber sido motrices en potencia, tal como las palabras de Aristóteles lo mostrarán, que estas dos partes no son ni generables ni destructibles, y que el agente respecto del recipiente es casi como la forma respecto de la materia, como luego se demostrará (CM III. 5, 406: 556-565). 
generar inteligibles, pero su acuerdo tiene una importante excepción: estos inteligibles no pueden ser cosas «abstractas» ${ }^{70}$.

En cuanto al entendimiento teórico, Averroes lo define como aquel que el entendimiento agente pone en el entendimiento material, igual que «el artesano pone las formas artificiales en los artefactos» ${ }^{71}$. Ocupa pues un estadio intermedio entre agente y paciente, y por esto es asimilable al entendimiento in habitu, como Averroes mismo indica ${ }^{72}$. El entendimiento teórico es nuestro tesoro de conocimientos, de inteligibles existentes en acto en el entendimiento (material). A pesar de su soporte único, son conocimientos individuales y que se desarrollan en cada hombre. Averroes aquí constata un hecho aparentemente contradictorio y difícil de explicar, según nos reconoce ${ }^{73}$. Básicamente, ve la razón de esta doble naturaleza del entendimiento teórico en el hecho de que un inteligible no es destructible en términos absolutos, sino en relación con cada individuo, de modo que podemos decir que el entendimiento teórico es uno para todos los hombres. Averroes llega a plantearse la hipótesis de la extinción de los conocimientos por causa de la extinción de los hombres en alguna zona de la tierra, hipótesis que descarta porque la sabiduría es innata a la especie ${ }^{74}$.

De todos modos, el entendimiento teórico no es el punto final, ya que los filósofos aspiran al conocimiento de los inteligibles en sí mismos, no como intentiones ni formas imaginadas, sino abstractas de toda materia. Podemos ir extrayendo inteligibles de los distintos niveles de formas, nos dice Averroes siguiendo a Avempace ${ }^{75}$, pero no podemos proceder de manera infinita, sino que nuestro conocimiento debe culminar en una forma abstracta o separada de la materia, en una «una quididad que no tiene quididad» ${ }^{76}$. Se trata de saber qué entendimiento es capaz de ello.

70 Aunque lo afirmemos así, del hecho de que se complete su acción de crear inteligibles solamente resulta el hecho de que se complete su acción de entenderlos, no el de entender las cosas abstractas, porque su intelección no se puede atribuir a un proceso de generación, ni ser producida por otro ente generado, por ejemplo, por el entendimiento in habitu, excepto de manera accidental. Si fuera posible, entonces lo generable se convertiría en eterno, como hemos dicho (CM III. 20, 489: 299-490: 306).

71 CM III.5, 389: 75-77.

72 CM III.5, 389: 78-80: «este tercer entendimiento [in habitu], el que pone el entendimiento agente en el entendimiento pasivo recipiente, y que es el entendimiento teórico».

CM III.20, 448: 129-132: «En cambio, Alejandro cree que el entendimiento in habitu (y que es el teórico) es distinto del entendimiento agente, y esto es lo que hay que creer, pues el arte es distinto del artefacto, y el agente, distinto del efecto (acto)».

73 Ahora bien, la segunda cuestión, la de cómo es posible que el entendimiento material sea uno numéricamente en todos los individuos humanos, ni generado ni destructible, pero que los inteligibles existentes en acto en el mismo (el entendimiento teórico) sean multiplicados por el número de individuos humanos, generados y destructibles por causa de la generación y destrucción de los dichos individuos es sumamente difícil y muy ambigua (CM III.5, 401: 424-402: 432).

74 Así será siempre que no se afirme que la disposición (dispositio) en la última perfección del hombre es igual que la disposición en los inteligibles comunes a todos, es decir, que el ser del mundo (esse mundanum) no se deshace del ser de un individuo determinado, pues no parece que esto sea imposible. Por el contrario, quien lo dice parece tener razón y puede convencer, y ello porque como la sabiduría es algo cuya naturaleza es existir en los hombres, de la manera como la de los oficios es existir en los hombres, se cree que es imposible que la ecumene abandone la filosofía, igual que es imposible que abandone los oficios naturales. Si alguna parte del mundo está falta de ellos, por ejemplo, el cuarto septentrional de la tierra, las otras cuartas partes no carecerán de ella, puesto que se ha demostrado que la ecumene es posible tanto en la parte septentrional como la meridional. (CM III. 5, 407: 605-408: 619).

75 Esto es, pues, lo que opinamos de los argumentos de los expositores peripatéticos en favor de que este objetivo es posible, es decir, entender las cosas abstractas en una última fase. Avempace trató mucho de esto, sobre todo en una epístola que llamó Conjunción del entendimiento con el hombre y para resolver esta cuestión se basó en lo siguiente: Afirma que los inteligibles teóricos son productos (facta), a continuación afirma que todo producto tiene una quididad, luego que en todo lo que tiene una quididad, el entendimiento tiene capacidad para extraerla, etc. (CM III.36, 490: 319-329).

76 No queda más que la tercera opción, que el entendimiento llegue a una quididad que no tiene quididad, tal quididad es la forma abstracta. Confirma esto a través de lo que Aristóteles suele decir en este tipo de demostraciones, a saber, que cuando hay que cortar el infinito, es mejor cortar al principio (CM III.36, 492: 382-387). 
Su respuesta es una forma compuesta - por extraña que sea la expresión, es la que utiliza- compuesta del entendimiento in habitu y del entendimiento agente ${ }^{77}$. El entendimiento material —nos recuerda ${ }^{78}$ — no podía unirse directamente al entendimiento agente, y el teórico tampoco es capaz, pero es condición necesaria para el conocimiento de las cosas abstractas. El entendimiento agente es ahora la forma determinante de un compuesto, el cual a su vez es nuestra forma última (forma postrema), y nuestra perfección ${ }^{79}$. Su posición no está libre de dudas que el mismo Averroes reconoce y afronta ${ }^{80}$ para considerar, finalmente, que se resuelven por una interpretación 'analógica' de la relación entre materia y forma, a saber, pues la materia es lo menos perfecto, en este caso el entendimiento teorético, y la forma es lo más perfecto, el entendimiento agente ${ }^{81}$. Los instrumentos de análisis que le proporciona la tradición aristotélica llegan a sus límites y solamente puede emplearlos de manera analógica, algo que más arriba hemos visto que hacía al definir el entendimiento material.

Con esto Averroes responde, en definitiva, a una cuestión que preocupaba a sus antecesores árabes, y en particular a Avempace: la conjunción del hombre con el entendimiento agente. El hecho de interponer el entendimiento in habitu y especulativo le da un carácter muy distinto. Frente a una tradición que busca esta conjunción en un estado místico al que se llega mediante prácticas ajenas a la ciencia, o en una acción divina, Averroes no ve más que la vía del esfuerzo científico, de la ciencia natural, para alcanzarla. La conjunción es gracias al entendimiento teorético, en un proceso de conocimiento científico, que culmina en el conocimiento del inteligible en cuanto tal, abstracto de materia ${ }^{82}$.

Debemos señalar que esta no es una posición exclusiva del Comentario Mayor, una obra tardía y de madurez. No mucho más tarde de 1169 , Averroes había redactado el epítome del De anima y un manuscrito cairota conteniendo las Sumas de las obras más importantes de Aristóteles $^{83}$ nos ha hecho llegar esta primera redacción. Averroes estaba bajo la influencia de

77 Nuestra forma última, gracias a la cual abstraemos los inteligibles y los entendemos, está compuesta del entendimiento in habitu y del entendimiento agente, tal como dicen Alejandro y Avempace, y es tal como nosotros pensamos que las palabras de Aristóteles lo dan a entender (CM III.36, 489: 294-298).

(No debemos confundir este conjunto de conocimientos con los principios o nociones comunes a la especie humana, y que son etemos por ser parte del entendimiento material).

78 Como para Avempace el entendimiento material es perecedero, algo perecedero podría comprender lo que es eterno, y otras absurdidades. Cfr. CM III.36, 493: 412-494: 426.

79 Está claro que esta tesis (positio) viene a ser el principio y fundamento de lo que queremos decir acerca de la posibilidad de conjunción [del entendimiento] con las cosas abstractas según Aristóteles, a saber, que nuestra forma última mediante la cual extraemos los inteligibles y los hacemos utilizando nuestra voluntad, está compuesta de entendimiento agente y de entendimiento in habitu (CM III.36, 490: 313-321).

80 Digamos, pues, que el argumento de que si nosotros obtenemos conclusiones a partir del entendimiento agente y de unas proposiciones, las proposiciones en relación con el entendimiento agente son casi una verdadera materia y un verdadero instrumento, yo digo que no es un argumento necesario. Solamente es-necesario bajo el aspecto (respectus) de que el entendimiento in habitu es comparado (assimiletur) con la materia y el agente, con la forma. Así pues ¿cuál es esta relación (respectus) y de dónde le viene al entendimiento agente el que mantenga esta relación con el entendimiento in habitu, a pesar de que el primero es eterno y él segundo generado y destructible? (CM III.36, 498: 539-549).

81 Una vez demostrada la conjunción que hay entre el entendimiento agente y el entendimiento material, podemos encontrar la manera cómo decir que el entendimiento agente es similar a la forma, y que el entendimiento in habitu es similar a la materia: Siempre que en dos cosas cuyo sujeto es el mismo, una es más perfecta que la otra, la relación de la más perfecta para con la menos perfecta tiene que ser como la relación de la forma para con la materia. En este sentido decimos que la analogía (proportio) entre la perfección primera de la facultad imaginativa y la perfección primera del sentido común es como la proporción entre la forma y la materia (CM III.36, 499: 567-577).

82 Está claro que entender el inteligible en cuanto tal es una parte de las ciencias teóricas, a saber, de la ciencịa natural, algo que también nos ha quedado claro en su examen (CM III.36, 494: 433-435).

83 Physica, De caelo, De gen. et cor, Meteorologica, De anima, Metaphysica. Se trata del manuscrito de la Biblioteca Nacional Egipcia, sección Hikma wa-Falsafa n 5 (antiguamente 4814). 
Avempace para quien el desarrollo humano culminaba necesariamente en la conjunción del hombre con el entendimiento agente en base a una ascensión de formas cada vez más espirituales. A pesar de esta influencia, no dudó ya en criticar a los sufíes y sus métodos al margen de la razón, y revindicó que el único camino hacia esta conjunción era el del esfuerzo demostrativo y científico ${ }^{84}$. De este periodo es también la segunda de las tres epístolas editadas y traducidas por J. Herz sobre la conjunción con el intelecto ${ }^{85}$, donde también excluye vías que no sean las del esfuerzo racional. En la madurez del Comentario Mayor, la cuestión de una hipotética conjunción perfecta y absoluta deja paso a la conjunción posible en la vida de cada hombre.

Los filósofos parisinos del siglo XIII, o los paduanos en el siglo XV leyeron correctamente a Averroes, pero sus intereses eran distintos de los que apreciamos en su comentario mayor al De anima. Fiel a Aristóteles, Averroes quiere explicar el proceso cognitivo partiendo de su esquemática distinción entre entendimiento agente y material, pero teniendo muy presentes las investigaciones de Alejandro de Afrodisias y de Temistio, entre los comentadores griego, y de Alfarabi y de Avempace, entre los pensadores musulmanes. Igualmente importante es para él su encaje en una visión del mundo, donde la especie humana es eterna, aunque sus individuos nazcan y mueran.

Hacer una lectura de sus comentarios al De anima buscando una respuesta a la cuestión de la inmortalidad del alma, no cabe duda que lleva a la conclusión de que según el sistema de Averroes aquí representado, la inmortalidad está garantizada sólo en cuanto a la especie. Por esto la lectura de sus seguidores medievales y renacentistas era correcta, pero estos no tenían en cuenta - quizá por no conocerlos- otros escritos de Averroes así como su actitud sinceramente religiosa, y musulmana, que implican una creencia en la inmortalidad individual. En cualquier caso, la preocupación de Averroes —este es mi argumento- en sus comentarios al De anima, y en particular, en el comentario mayor, es explicar el proceso cognitivo y establecer que no hay una conjunción inmediata con el entendimiento agente, sino un acercamiento a través del esfuerzo individual para conseguir la ciencia, sinónimo de filosofía teorética. Es algo, sin duda, relacionado con la idea de felicidad como perfección humana, y en que todos los aristotélicos estaban de acuerdo:

84 Averroes estaba preocupado por la conjunción del hombre con el entendimiento agente siguiendo los pasos de Avempace. Al problema le dedicó algunos opúsculos, y en su epítome, Talkhị̂ kitâb an-nafs, ed. Aḥmad Fu'âd al-Ahwânî, Cairo, 1950, pp. 94-95, leemos:

[Puesto que] se ha demostrado que esta conjunción no es por causa de una perfección natural, tenemos que admitir que es una perfección bajo el aspecto como se dice que las formas separadas son perfección para los cuerpos [p. 95] circulares, y en la ciencia de la naturaleza hemos explicado cómo es esta relación. En resumen, es una perfección revelando la relación de la perfección de la naturaleza que es su materia.

Si se considera el caso (hâl) del hombre en esta conjunción, se manifiesta que es un milagro natural, y que al hombre le ocurre que es como compuesto de lo eterno y lo destructible, de la manera como existen los términos medios en los géneros correlativos, como el intermedio entre planta y animal, $o$ animal y hombre. Esta existencia revela la existencia que es propia del hombre en cuanto es hombre. En esta situación se producen el asombro y la estupefacción, y en general, la suspensión de las actividades naturales en las facultades del alma, de tal modo que se dice que asciende en los espíritus [de los hombres], y en resumen es una gracia divina. Este es el estado de unificación que buscan los sufíes, y está claro que ellos no lo alcanzan en absoluto, puesto que para alcanzarlo es imprescindible saber las ciencias naturales.

85 Drei Abhandlungen ïber die Conjunction des separaten Intellectes mit dem Menschen von Averroes (Vater und Sohn) Berín, 1869. Traducción francesa de Marc Geoffroy en Averroès, La béatitude de l'âme (con C. Steel), París: Vrin, 2001. 
Debes saber que la práctica y el ejercicio son causa de que la facultad (potentia) del entendimiento agente existente en nosotros, se manifieste para abstraer, y de que la facultad del entendimiento material se manifieste para recibir [inteligibles] ${ }^{86}$.

Josep Puig Montada Departamento de Filología Árabe

Facultad de Filología

Universidad Complutense

28040 Madrid

puigmont@filol.ucm.es

86 Digo que son causas debido al hábito que existe - gracias a la práctica y al ejercicio-en un entendimiento pasivo y corruptible, que Aristóteles llamó passibilem, y dijo claramente que se destruía. (CM III. 20, 453: 301-454: 305). 